\title{
A LEI MARIA DA PENHA E OS DESAFIOS DA ATUAÇÃO POLICIAL
}

\author{
THE MARIA DA PENHA LAW AND THE CHALLENGES OF POLICE
}

\section{LA LEY MARIA DA PENA Y LOS DESAFÍOS DE LA POLICÍA}

Ana Pereira dos Santos ${ }^{1}$

Luciano Rodrigues Costa ${ }^{2}$

\begin{abstract}
Resumo
Este artigo propõe discutir a atuação de policiais na construção da queixa de violência doméstica de mulheres no cotidiano de uma delegacia de polícia. A partir de observação participante e imersão em uma delegacia, busca-se analisar as novas demandas para a atuação policial. A resposta coercitiva, que sempre marcou o lugar social da polícia brasileira, se vê confrontada, a partir de mecanismos políticos institucionais como a Lei Maria da Penha, a construir uma atuação educativa que flexibilize a lógica masculina própria da instituição. Marcadores de gênero e diferentes performances atravessam o trabalho de um (a) profissional que se vê desafiado (a) a compor novos arranjos subjetivos e saberes da prática que questionem o já consolidado aprendizado advindo da Academia de polícia.
\end{abstract}

Palavras-chave: Violência contra a mulher. Polícia. Políticas inclusivas de gênero.

\begin{abstract}
This article aims at discussing the role of police officers in the construction of the complaint of domestic violence of women in the daily life of a police station. Based on participant observation and immersion in a police station, it was sought to analyze the new demands of police action. The coercive response, which has always marked the social place of the Brazilian police, is confronted, based on institutional political mechanisms such as the Maria da Penha Law, to build na educational action that will make the institution's own male logic more flexible. Gender markers and different performances cross the work of a police force that has been challenged to compose new subjective arrangements and knowledge of the practice that question the already consolidated learning from the Police Academy.
\end{abstract}

Keywords: Violence against women. Police. Gender-inclusive policies.

\section{Resumen}

En este artículo se propone discutir el papel de los agentes de la policía en la construcción de denuncias sobre violencia doméstica de las mujeres. Con base en la observación participante y la inserción en el quehacer cotidiano de una estación de policía, buscamos analizar los nuevos desafíos de la acción policial. La respuesta coercitiva, que ha marcado siempre la situación social de la policía brasileña, está siendo confrontada mediante mecanismos políticos institucionales, como la Ley Maria da Penha, con el objetivo de lograr una actuación más educativa que ayude a flexibilizar la lógica masculina de la institución. Factores como marcadores de géneros y diferentes formas de actuación, tanto dos agentes policiales como de las víctimas, afectan el trabajo de la policía; esto conlleva el desafío de buscar nuevos métodos subjetivos y prácticos que se contraponen al aprendizaje consolidado de la academia de policía.

Palabras clave: La violencia contra las mujeres. Policía. Políticas de género inclusivas

\footnotetext{
${ }^{1}$ Psicóloga, doutora em Psicologia pela PUC Minas. Pós-doutoranda em Saúde Coletiva - Instituto René Rachou - Fiocruz Minas. E-mail: anapsant3@gmail.com

${ }^{2}$ Sociólogo, doutor em Ciências Sociais pela UNICAMP. Professor adjunto da Universidade Federal de Viçosa. Email: Ircosta00@gmail.com
} 


\section{INTRODUÇÃO}

A reflexão proposta neste artigo constitui uma etnografia, fruto de uma pesquisa de observação participante em uma delegacia não especializada em uma cidade do interior de Minas Gerais. Tendo como objeto de observação a construção da queixa de violência doméstica de mulheres, buscou-se compreender as produções de subjetividades, os fluxos e os processos educativos que podem advir de um encontro marcado por variáveis importantes: a implementação da Lei Maria da Penha (BRASIL, 2006), particularidades culturais, políticas e sociais próprias da cidade que interferem no cotidiano das ações policiais.

A pesquisa se desenvolveu no cenário de efetivação da Lei Maria da Penha no Brasil. Junto com normativas do poder executivo que orientam a proteção da mulher no âmbito do executivo como, por exemplo, o Plano Nacional de Políticas para Mulheres (BRASIL, 2013) e a Política Nacional de Enfrentamento à Violência Contra as Mulheres (BRASIL, 2011), a lei estabelece novas condições para o enfrentamento da violência contra a mulher nos serviços de proteção. Reconhecida como uma importante ação afirmativa do legislativo brasileiro, destacase por prever uma atuação imediata na proteção da mulher, possibilitando a aplicação de Medidas Protetivas de urgência que garantem, entre outras, o afastamento do agressor com possibilidade de prisão caso seja descumprida a determinação policial ou judicial.

Entre as principais inovações da nova legislação está a tipificação e definição da violência doméstica e familiar contra a mulher. A violência baseada no gênero deve ter sido praticada no âmbito doméstico, familiar ou em relação íntima de afeto. Nesse sentido, só se enquadra na lei agressões que tenham como pano de fundo as diferenças culturais atribuídas ao homem e à mulher, em que claramente se estabelece uma relação de dominação no qual o poder masculino prevalece sobre o feminino. Nesse cenário, estão consolidados papéis rígidos e pré-definidos impostos aos homens e às mulheres, reforçando sempre uma tradição patriarcal e prejudicial à autonomia feminina e reafirmando uma relação de sujeição e prejuízos materiais, psicológicos e financeiros para a mulher.

A Lei Maria da Penha pretende construir condições de igualdade entre homens e mulheres, punição a agressores, garantir a integridade física e proteção aos filhos da mulher agredida. São inúmeras as dificuldades na operacionalização desta novidade jurídica no contexto de uma delegacia não especializada em uma cidade do interior. Entre elas, a deficiência de agentes policiais familiarizados com a temática. Nesse sentido, a Lei Maria da Penha possui intrinsecamente uma dimensão educativa, em que novas formas de pensar e agir 
precisam ser construídas. Não menos importante é a organização de um aparato policial e jurídico que contemple todas as especificidades da implantação dessa ação afirmativa contida na legislação. Espera-se mudanças nas estruturas de pensamento e a construção de um novo arcabouço de saberes que ressignifique não só os lugares socialmente construídos para a mulher em situação de violência e para o agressor, como também avance na concepção de proteção no contexto das política sociais.

Respeitando os princípios de uma etnografia, a pesquisa revela um mundo social, orientado por uma cultura, uma linguagem e questões relacionais próprias deste coletivo de pessoas. Um processo de institucionalização construído pela mulher em situação de violência, os profissionais envolvidos, a política de segurança pública e as variadas formas de interpretála e implementá-la. Sendo assim, o estudo de caso aqui proposto, por um lado, demonstra especificidades da delegacia pesquisada. Ainda assim, revela o desafio da implementação de políticas para mulheres em situação de violência, sobretudo quando problematizamos a interiorização das políticas especializadas para cidades de pequeno e médio porte.

\section{CENÁRIO DE ESTUDO}

O estudo foi realizado em Viçosa, zona da Mata de Minas Gerais, cidade com aproximadamente setenta e nove mil habitantes. Além da população local, Viçosa comporta uma universidade federal, o que permite um aumento significativo de sua população. A flutuação do número de habitantes é uma variável que, de diferentes formas, agrava os números e os tipos de violência contra mulheres no município. Por outro lado, dispor de um aparato universitário público faz com que a cidade seja impulsionada para a constituição de políticas públicas que, muitas vezes, não estão nas pautas dos governos como prioritárias.

No que tange as políticas especializadas de atendimento à mulher o município, na época do estudo não havia atendimento específico para as mulheres no âmbito da segurança pública. No entanto, já existia serviços de saúde que estavam se especializando para o atendimento a estes casos, uma Defensoria Pública especializada e sensibilizada para acolher a mulher e acompanhar os casos, além da Casa das Mulheres, projeto de extensão criado em parceria com a Universidade Federal de Viçosa, Defensoria Pública e Conselho Municipal de Direitos das Mulheres. A Casa das Mulheres propôs, de 2010 a 2020, diante da falta de equipamentos especializados para acolhimento e orientação das mulheres no âmbito jurídico e psicossocial, uma tecnologia social própria para o atendimento e acompanhamento deste público. Além disso, oferecia formação permanente para os trabalhadores dos serviços e estratégias de 
mobilização e diálogo para o fortalecimento da rede de atenção à mulher em situação de violência.

Atualmente, no âmbito da segurança pública, o município conta com uma delegada para atendimento das mulheres em situação de violência que atende dentro da Delegacia de Polícia da cidade e também com um Posto de Polícia Integrada (PPI). Recentemente foi implantado o Serviço de Prevenção à Violência Doméstica (PPVD) desenvolvido pela Polícia Militar. Para atendimento psicológico e jurídico a população conta com o Núcleo de Atenção à Mulher em Situação de Violência que é mantido pelo governo municipal e pretende funcionar como um Centro de Referência da Mulher (CRM), equipamento público pautado nas normativas do governo federal. A cidade ainda oferece serviços de saúde que continuam sendo orientados para especializarem o atendimento da mulher em situação de violência, incluindo a violência sexual, e um Serviço, ainda em implementação, de Coleta de Vestígios para responsabilização penal do agressor.

\section{INTERLOCUÇÕES TEÓRICAS E METODOLÓGICAS}

A pesquisa foi constituída essencialmente por uma Observação Participante. Tal proposta se configura em uma investigação eminentemente indutiva, em que não houve nenhuma categoria ou hipótese que não tenha sido construída em diálogo com o campo empírico. Como complemento da observação participante foram realizadas entrevistas semiestruturadas, fundamentais para a coleta e interpretação dos dados. $O$ conjunto de métodos e técnicas utilizadas possibilitou a apresentação dos resultados na forma de uma etnografia.

Na imersão em campo foi possível acompanhar o primeiro momento da queixa, quando são realizados os boletins de ocorrências, hoje chamado registro de defesa social, e a representação do crime. Foi possível presenciar o encontro da mulher em situação de violência com o acolhimento na recepção, com os escrivães e delegados. Neste recorte metodológico foram observados os primeiros conflitos entre policiais e mulheres, assim como falas e atitudes espontâneas que surgem desta experiência.

Como interlocução teórica, os estudos sobre o cotidiano apresentaram-se como campo epistemológico coerente aos objetivos aqui propostos. Entendendo o cotidiano como a arte de fazer, podemos compreendê-lo como "as experiências particulares, as frequentações, as solidariedades e as lutas que organizam o espaço onde as narrativas vão abrindo um caminho" (CERTEAU,1994, p.35). Espaço/tempo onde os conceitos de subjetivo e objetivo não podem 
ser usados com tanto desembaraço já que não estamos no campo das certezas, mas das construções efêmeras, transitórias, continuadas e que nem por isso deixam de afetar os sujeitos e seus modos de vida.

Dessa maneira, os "praticantes do cotidiano" são todos aqueles que nele convivem e que nele interferem (CERTEAU, 1994). Não há centralidades onde possam ser localizadas as produções de saber ou mesmo poder, já que o que temos é um rizoma de conexões em plena produção do novo e dos acontecimentos que marcam a construção dos fatos sociais. $O$ pesquisador não está amparado em um roteiro prévio em que possa sustentar seu trabalho de pesquisa, mas confrontado com a possibilidade de conviver com os praticantes e estar disposto a uma co-construção do método (GARCIA, 2003).

Aliado a isso, a proposta de se pensar a subjetividade enquanto um processo contínuo e condicionado a contingências sociais, econômicas e políticas, faz parte do arcabouço teórico que orienta nossas interpretações. A partir de Foucault (1994, 2002, 2003, 2008), Gilles Deleuze e Félix Guattari (1995) e Rolnik (2011) compreendemos que a subjetividade não é algo produzido de modo individual, mas em consonância com contingências e encontros que a constituem e que podem ter a potência de determiná-la. Falamos de uma subjetividade que está em constante mudança e que cria novas facetas a partir das vivências, dos afetamentos e das circunstâncias de vida que se apresentam. Ou seja, uma subjetividade que não remete só ao indivíduo, mas também a acontecimentos e situações da ordem do coletivo e dos discursos normativos que afetam os modos de vida.

É importante notar que tensionamentos atuais, como a própria Lei Maria da Penha, tem produzido desestabilizações em espaços institucionais importantes como a delegacia. Com as mudanças, não é possível olhar para esta violência, analisá-la e atender suas demandas da mesma forma que fazíamos antes do surgimento dos novos aparatos técnicos e legais. No entanto, embora haja o apelo para a transformação das instituições, constituí-la é um processo individual e coletivo, com uma temporalidade que nem sempre responde às urgências dos problemas sociais.

No caso do atendimento policial à mulher em situação de violência, um dos principais recursos para inibir a violência está na proteção garantida pela política de segurança pública. Entender o fenômeno levando em consideração a categoria gênero é uma exigência e um desafio para que avancemos na constituição de uma polícia que não leia e responda a este crime a partir, apenas, da lógica repressora. Gênero enquanto categoria de análise proporciona a leitura das relações de poder e, portanto, de dominação no que tange as diferenças sexuais (SCOTT, 1995). Sendo uma primeira forma de dar sentido às relações sociais, na nossa 
sociedade o gênero hierarquiza e estabelece categorias fixas, subordinando tudo que remeta ao feminino ao poder masculino.

Quando a mulher chega a uma delegacia para dar queixa da sua violência, provoca as diversas representações do que é uma mulher, do que é um casamento, uma família, uma mulher agredida, do que é um homem, uma queixa de violência, entre tantas outras construções culturais que atravessam seu pedido. Se o policial poderia avançar na compreensão da violência pautando um saber que interaja com as normativas atuais e considere a mulher livre e autônoma para fazer suas escolhas, o que veremos no decorrer da pesquisa é uma instituição que se abre para a legislação, mas não altera sua cultura institucional, alijando a mulher de um atendimento adequado à sua condição de sujeito de direitos e plena cidadania.

O conceito de 'performance' de Butler (2003) se tornou um eixo central para nossas análises. Para a autora, performatizar o gênero é a repetição de atos dentro de uma estrutura de regulação. Não necessariamente inovadora, a performance do gênero carrega consigo uma normatividade compartilhada socialmente que oculta, e ao mesmo tempo revela, uma cena de originalidade e repetição. O momento da denúncia de violência doméstica de mulheres adultas em uma delegacia é um acontecimento eminentemente performativo do gênero. Em um ambiente cuja lógica de organização das normas possui um ordenamento masculino, falocêntrico e heteronormativo, nos perguntamos neste trabalho: como os policiais performatizam e compreendem os códigos de gênero diante do desafio de atenderem cotidianamente uma demanda na qual não estão preparados?

Os procedimentos metodológicos foram submetidos e aprovados pelo Comitê de Ética em Pesquisa com Seres Humanos da Universidade Federal de Viçosa, parecer $n^{\circ} 1.536 .928$.

\section{PODE A POLÍCIA EDUCAR?}

Durante a pesquisa, uma frase interessante foi proferida por um investigador que atua há vários anos na polícia civil, manifestando de forma clara e espontânea, durante o atendimento de um caso, o que significa para este grupo de policial quando uma mulher não quer ver seu agressor preso. Revelam que querem seus companheiros "assustados" e "apertados" por um determinado tipo de policial que se encontra no imaginário social de algumas delas. Homens que irão usar a força do corpo e da farda para protegê-las, mas sem interferir na relação que o casal estabelece. 
Neste caso, uma mulher se queixava do marido que teria sido agressivo na noite anterior. Havia batido nela com uma vassoura, seu rosto estava visivelmente machucado e teria, inclusive, a ameaçado de sofrer outras agressões mais graves. Durante o atendimento, foram feitos todos os procedimentos necessários: boletim de ocorrência e representação do crime para posterior abertura de inquérito. Ao final do atendimento, quando já estávamos saindo da sala, de forma repentina ela falou: "Olha, senhor policial, na verdade, eu não queria nada de ruim para ele não! Acho que não vamos fazer nada não, deixa isso para lá, o que eu queria mesmo era dar um bom susto nele, era isso. Mas desta forma que foi feita aí, vai complicar a vida dele e da gente!". O policial respondeu:

Minha senhora, eu vou falar uma coisa, as meninas da Casa das Mulheres sabem que
eu não gosto de fazer esse tipo de atendimento, mas fiz a pedido delas e do delegado.
Aqui não tem fantasma para dar susto ou alicate para dar aperto. Aqui é a polícia! E
polícia serve para prender, para constituir provas para incriminar criminoso. Tudo o que a
senhora contou aqui é muito grave. A polícia agora vai agir!

Não ser "fantasma" e nem "alicate" é uma posição de recusa do policial quando a mulher sugere outra atuação que não passe pelos moldes clássicos do trabalho da polícia brasileira. Ela não pede, necessariamente, uma ação de coerção ou de violência, mas uma atitude educativa. As mulheres solicitam que a polícia realize com seus companheiros um processo de ressocialização, realocando os lugares de poder na relação e 'ensinando' que uma parceria amorosa não pode ser violenta. A expectativa depositada no trabalho policial é compatível com a esperança de mudança que pode advir das atitudes do companheiro, sem que haja ameaças de rompimento no projeto de casamento e da constituição familiar imaginada.

Em uma das entrevistas, uma policial problematizou como seus colegas recebem esta demanda. Considera que as mulheres agredidas chegam com uma solicitação que eles, geralmente, fazem piada, como, por exemplo, o pedido de que 'corrijam' seus companheiros de outra forma que não seja através da prisão. Rindo, ela me falava que isso não tinha lógica pois diante de um homem machista, que passou a vida toda acreditando que podia bater em mulheres, por que uma conversa com o policial poderia mudar o seu comportamento? O motivo de virar piada, segundo a policial entrevistada, é porque os policiais não enxergam saída eficaz nessa estratégia que a mulher aponta. Ela me diz, inclusive, que acredita mais em terapia de casal no que em uma polícia educativa, mostrando uma percepção realista da atuação policial que parecia conhecer bem.

Diante da ausência de novas categorias que os auxiliem na construção de saberes distintos para a compreensão da violência doméstica, é a partir da ironia, muitas vezes, que se interpreta o pedido feminino de proteção, recusando transformar a violência íntima em 
problema penal. Dessa forma, os policiais pesquisados refazem as mesmas estratégias de trabalho dos outros crimes para lidar com as queixas de violência de mulheres. Eles evitam pensar em uma intervenção mais política no ambiente social e acabam, novamente, respondendo ao fetiche militarizado de segurança pública para resolver problemas de diferentes esferas e complexidades.

A mesma policial, em uma fala que desqualifica o sistema de justiça e a segurança pública, relata que hoje está muito fácil para os homens quando eles agridem as mulheres. Ela diz que escuta dos homens que atende "se eu bater nela lá, não tem problema não, eu vou lá no fórum, não vou poder mais chegar perto dela e tudo bem". Ela ainda destaca que considera que a noção de punição está muito suave para o benefício do crime. Acredita que a Medida Protetiva só funciona para a pessoa que tem um mínimo de respeito, de noção de família, de educação. Diz, finalmente, que a lei só funciona para quem a respeita e para quem não precisa dela.

Na perspectiva dos policiais, o atendimento das mulheres em situação de violência deve se encaixar no hall de saberes aprendidos na Academia de Polícia e utilizados no já consolidado cotidiano de trabalho. A necessidade da construção de novos saberes se mostra distante e aparece em formato de queixas. Poucos se dispõem a encontrar, por iniciativa própria, caminhos de aprendizado. Santos (1997) discute a constituição da organização policial enquanto um ofício específico e marcado por duplicidades. Além de possuir o monopólio da violência física legítima (WEBER, 1999), a instituição foi determinada para produzir consensos. Como máquina repressiva do estado, a polícia se insere no processo de consolidação democrática da sociedade com a atribuição legítima do exercício da violência e com a real possibilidade do excesso do poder.

Antônio Luiz Paixão (1982) discute as funções políticas da polícia, destacando como ela tem desempenhado suas atribuições e exercido o poder que a sociedade the confere. Cuidar da repressão política, ser um cão de guarda das classes dominantes e implementar a violência do Estado, seja ela legítima ou ilegítima, encontram-se entre as atribuições que configuram a identidade policial. Essa violência que organiza a instituição confere à polícia poder de neutralizar, ou mesmo eliminar, dissidentes políticos, domesticar as classes subalternas e manipular ideologicamente a classe média.

Para Paixão (1982), não é o uso de categorias legais que orienta o trabalho da polícia (o que talvez explique as dificuldades para incorporar ao saber policial outras perspectivas de leituras sobre a violência doméstica), mas ideologias e estereótipos formulados organizacionalmente, tornando, portanto, segundo o autor, mais econômica a ação policial. 
Algumas características marcam a atuação policial: centralização, hierarquia, disciplina, princípio de carreira, universalismo e profissionalismo. Essas características, mais do que marcar a formação do policial e sua atuação, aproximam a polícia do modelo "quase-militar".

Há um tipo de racionalidade prática que marca a atuação do policial. Nela aparece tanto o uso de simplificações tipológicas do mercado criminoso quanto a "suspensão" de categorias em encontros concretos com "tipos". Dessa forma, a atividade prática irá se constituir com o uso e a ampliação da cultura organizacional, sendo que o momento do trabalho propriamente dito e o encontro com as queixas serão ocasiões de mobilização, utilização, teste ou ampliação de um estoque preexistente de conhecimento (PAIXÃO, 1982). A "imagem-guerreira", fruto da atuação "quase militar" do policial, ajuda a sustentar uma ideia de que o policial é o protetor da sociedade. Se a justiça é avaliada como lenta, ao policial cabe a responsabilidade de assumir também os papéis judiciários. O papel político desempenhado pela polícia é discutido: ser "linha de frente", ao impor seu modelo de ordem na periferia social, é também ser "linha de frente" do Estado.

Controlar o crime e a desordem seria os principais indicadores do trabalho policial no modelo que temos atualmente. Diante da democratização das estruturas políticas (SANTOS, 1997), a polícia, com sua concepção eminentemente reativa, apresenta seus fracassos em algumas condições particulares de crimes (PONCIONI, 2005). Problematizar a função da delegacia e acentuar como primordiais os direitos da mulher na queixa de violência doméstica, ainda são discussões incipientes nos saberes produzidos pelos policiais que tentam conceituar esse tipo de violência. Se, por um lado, eles desacreditam dos aparatos jurídicos e da segurança pública para regular estes casos, por outro, eles acreditam que o problema só pode ser resolvido pela via da conciliação ou da psicologização do fenômeno. Tal atribuição torna-se responsabilidade de outros equipamentos da rede de atendimento e não da polícia. Desjudicializar o que recentemente foi colocado nos termos da lei é uma ideia constante nas observações dos policiais. Como afirma um policial:

O papel nosso é muito limitado. É colocada para a mulher uma Medida Protetiva, aí o cara vai lá, liga para mulher! Depois das 18 horas aqui a gente não pode fazer nada, a polícia militar muitas vezes não vai. Mesmo se o cara estiver fazendo alguma coisa de verdade com ela, a polícia não vai. Sabe por quê? Porque toda hora liga, toda hora fica essa amolação, acaba que a polícia não vai. Mas agora tem o Projeto Casa das Mulheres aí que dá um aconselhamento. Isso eu acho mais importante do que a própria Medida Protetiva. A Medida dá uma falsa segurança no meu modo de ver, porque o Estado não protege ninguém. 
Em outra entrevista, um dos delegados também analisou a ambiguidade na queixa feminina. Citou o ciclo da violência ${ }^{3}$ como a forma de exemplificar como funciona o apelo da mulher à justiça e, em seguida, sua desistência. Diante dessa instabilidade, ele não considera que a justiça possa resolver, mas sim a política de assistência social, ao oferecer um atendimento psicossocial. Dessa forma, como aponta o entrevistado, de forma pragmática, um profissional como um psicólogo poderia levar o casal a se separar, acabando com a situação de violência.

Um investigador de polícia, também entrevistado, não reconhece o compromisso do trabalho policial no atendimento da violência contra a mulher. Ele diz:

\begin{abstract}
É uma desvalorização do profissional. Aquele tempo em que eu fiquei ali, gastando com ela, eu poderia atender outro caso. Uma vítima de um furto, de um roubo, de um estupro. Ou seja, ela não quer uma solução policial para o problema, ela está querendo que chame o sujeito aqui, que dê uma chamada no cara, e isso não é a nossa função. $A$ função da polícia é prender! A função específica da polícia judiciária é arrecadar provas e meios para que o ministério público denuncie e o judiciário condene. Então, as pessoas veem ainda a polícia como trinta anos atrás, da forma da ditadura, que pegava a torto e a direito, dava uma prensa, agredia as pessoas, sem ter uma finalidade na legalidade que é o inquérito e a prisão.
\end{abstract}

A racionalidade e os modelos de compreensão dos policiais não atingem a complexidade dos casos de violência contra a mulher, vistos como de menor relevância e perda de tempo. A ausência de uma leitura de gênero que os convide a pensar sobre a própria masculinidade, a feminilidade, assim como sobre o poder, é um desafio importante que, se não assumido, torna comprometido o atendimento. Além disso, a premissa da repressão os faz avaliar que a Lei Maria da Penha, como nos apontou Silvia, é branda, não alcança os objetivos (já conhecidos e institucionalmente compartilhados) da responsabilização.

A defesa e a desqualificação, por parte dos policiais, parecem ocupar um lugar mais destacado que os incômodos e as perguntas que poderiam mobilizar novas formas de intervenção. $\mathrm{Na}$ fala dos entrevistados, a violência contra a mulher é um problema para outros saberes e não para uma atuação interdisciplinar que inclui a segurança pública. O poder hegemônico que impera na instituição tampouco compreende as vacilações de mulheres embaraçadas entre a possibilidade de liberdade e o legado de lealdade a uma ordem

\footnotetext{
${ }^{3}$ Formulado pela psicóloga americana Lenore Walker, a teoria do ciclo da violência é comumente usada tanto na formação de profissionais que atuam em políticas públicas para compreenderem as oscilações da mulher na decisão em denunciar a violência, quanto em cartilhas que informam a população sobre a violência doméstica, suas formas e possibilidades de saída do ciclo violento. A teoria compreende, principalmente, três fases: aumento da tensão, o ato de violência e o arrependimento seguido de um comportamento carinhoso. Em muitos casos, a mulher encontra-se presa neste circuito, tomando decisões em momento limites e recuando quando enxerga possibilidades de conciliação e respeito na relação.
} 
eminentemente masculina, ainda determinante e definidora das construções sociais e das formas de se constituir homem e mulher.

\section{“AMANDO E APANHANDO": A AMBIGUIDADE DA QUEIXA DA MULHER EM SITUAÇÃO DE VIOLÊNCIA}

A história a seguir foi narrada por uma policial. Silvia ${ }^{4}$ conheceu Roberta e, inclusive, acompanhou suas queixas por algum tempo na instituição. Sua trajetória de pedidos de proteção, boletins de ocorrências e representações, mas, sobretudo, suas desistências, a colocam em lugares diferentes no imaginário policial. O mesmo acontece às outras mulheres que desistem de denunciar seus agressores: gostam de apanhar? Apaixonadas? Passivas?

As constantes brigas faziam com que Roberta fosse constantemente à delegacia prestar queixa contra seu marido e, assim que os conflitos se acalmavam, ela retornava querendo desistir do pedido que havia registrado. Existia, inclusive, na época do fato, a possibilidade de pagamento de fiança, recurso que Roberta fez uso por várias vezes. Entre estas várias denúncias, houve uma por flagrante e seu companheiro foi detido no exato momento em que a agredia. A polícia fez todo o procedimento necessário e iria encaminhar o companheiro de Roberta para o presídio da cidade quando ela chegou acompanhada de um advogado solicitando aos policiais que não prendesse seu marido. Os policiais que acompanharam o caso, principalmente o delegado, revoltaram-se com a postura de Roberta. Segundo Silvia, os procedimentos de flagrante são extremamente trabalhosos e, no contexto da organização, é preciso que os policiais cancelem suas tarefas para atenderem a esta prioridade. Isso quer dizer cancelar depoimentos agendados, atrasar entregas de documentos urgentes e organizar uma série de procedimentos para justificar a prisão em flagrante.

Quando deste fato, Roberta assinou o desinteresse e voltou com o companheiro para casa. Silvia explicou que a indignação do delegado era em função de que, semanas antes, o agressor a teria machucado depois de um empurrão na escada. Mas o que mais impressionou Silvia foi a frase utilizada por Roberta para resumir seu relacionamento e sua situação naquele momento. As duas se encontraram um dia na recepção da delegacia depois de muito tempo sem se verem. Quando Silvia perguntou para Roberta como ela estava, ouviu uma resposta sorridente: "Amando e apanhando".

A frase foi única, mas a história de Roberta se repete cotidianamente na delegacia. As perguntas: "O que elas querem?" ou "O que esperam do atendimento da policial?" foram as

${ }^{4}$ Visando o anonimato das pessoas entrevistadas, todos os nomes mencionados são fictícios. 
mais ouvidas durante o período da pesquisa. Embaraçados com as recusas femininas para concluir a denúncia de seus companheiros, ou com os diversos registros policiais de episódios de violência diferenciados, a delegacia se debate com este 'enigma' que, pelos corredores, ou a partir dos saberes da prática, são respondidos de várias formas. A maioria dessas respostas culpabiliza a mulher ou mesmo não operam alguma construção de saber significativa que possa alcançar a compreensão do caso. As dúvidas que elas suscitam nos abrem caminhos para questionarmos o que significa o recurso feminino a polícia (BRANDÃO, 1998) e quais as possíveis motivações que fazem com que as mulheres denunciem a violência doméstica.

Para os policiais já está, de certa forma, fadado ao fracasso alguns casos em que eles precisariam investir na apuração de provas e na construção do inquérito policial. A equação, a princípio, seria simples: se elas foram agredidas, se estão insatisfeitas com a relação e com o parceiro, logo, vão se separar quando da primeira agressão. Ou, no máximo, na segunda, já que deram uma chance ao companheiro e ele novamente a desrespeitou.

Durante a pesquisa de campo, o termo "reparação" entrou em cena para tentar esclarecer o vai e volta da queixa de violência por parte das mulheres. A ideia de reparar é interessante não só porque contrapõe a premissa de "romper" como, também, lança luz aos dois sujeitos da construção do laço violento: a mulher e o agressor. Os policiais esperam que venha junto com a queixa uma atitude de rompimento com a violência e com a relação. Quando isso não acontece, o que é comum na maioria dos casos, ao invés de sofisticarem a compreensão da violência, a repetição é recebida como desconsideração com o trabalho policial. As mulheres não só denunciam e voltam a se relacionar inúmeras vezes com o mesmo parceiro que as agridem como, também, denunciam mais de um companheiro por violência sofrida.

A complexidade de uma queixa de violência doméstica extrapola o entendimento simples de que uma vez agredida, nunca mais será suportada outra violência. O que se vê é um histórico longo e bastante desafiador para que os operadores da segurança pública possam lêlo a partir dos mesmos saberes cristalizados e institucionais que possuem para outros crimes. Cabe compreender porque uma mulher que denuncia seu companheiro não quer, necessariamente, incriminá-lo, mas reestabelecer, em outros termos, sua relação amorosa.

Suely Rolnik (2011), quando reflete sobre os modos de subjetivação de mulheres e seus aprisionamentos, utiliza da metáfora das "noivinhas" para problematizar as questões do feminino na contemporaneidade. Aponta as diversas máscaras que o feminino utiliza no jogo do encontro com o masculino. Nesse movimento de múltiplas identidades, os afetos são plenamente vividos em constantes fluxos de desterritorialização e territorialização da 
subjetividade que está em contínuos processos de mudança. As "noivinhas", para Rolnik (2011), são figuras do feminino que surgem ainda em 1950 em meio ao fortalecimento do regime fordista e disciplinar. Esta identidade faz a mulher girar como um peão em torno da figura masculina, e é dessa referência que ela extrai sua dignidade e suas possibilidades de estruturar-se psíquica e socialmente. A partir de 1960, com os novos regimes disciplinares que surgem com a época, a estrutura da família burguesa vai se diluindo e junto com ela a figura da "noivinha". Desse movimento, outras figuras de subjetividade surgem tentando não só transformar as estratégias de desejo produzidas até então, como gestar uma subjetividade flexível e cada vez mais moldada pela lógica capitalista.

Se o patriarcado é uma estrutura de poder e controle que se organiza a partir das instituições como a família, o sistema de justiça, a política e a polícia, como tentamos problematizar neste texto, a mulher já nasce com sua máscara pronta. Se não for a de "noivinha”, como nos aponta Rolnik (2011), alguma outra, produzida por um sistema opressor, pode sujeitar a mulher a uma condição subalterna. A saída para libertar-se do falocentrismo que submete o feminino à norma masculina, como aponta a autora, seria a produção de constantes deslocamentos subjetivos, a construção de territórios existenciais marcados pela flexibilidade, que, quando conectados a outras formas existenciais, podem promover processos de subjetivação singulares.

Nesse sentido, em uma sociedade constituída a partir do patriarcado, haverá sempre o risco da mulher conceber sua existência encaixando-se em expectativas sociais pré-existentes. A saída, portanto, seria experimentar diferentes máscaras, ocupando e desocupando possibilidades identitárias que promovam encontros, ventile liberdade e a possibilite transitar por diferentes formas de existir e reagir a dominação. Fazer das máscaras sociais disponíveis para as mulheres a sua essência é se contrapor ao movimento de desestabilização que é condição da liberdade feminina. Uma intensa produção de formas de existir, driblando, através da produção de novos territórios existenciais, o risco de colar uma só máscara, sempre à mão, em seu rosto. Abdala (2011) considera que a mulher faz o uso da delegacia como um "recurso simbólico" na tentativa de garantir um interditor que aponte uma saída que não seja pela via da violência. Nesse sentido, as mulheres podem não estar buscando, necessariamente, uma punição para a queixa anunciada, mas a restauração de uma ordem que confere sentido não só à relação, como também a sua existência social (BRANDÃO, 2006). É o meio que possuem para realocarem os códigos de gênero dentro da relação e continuarem em um projeto de amor, já que existir sozinha, portanto, responder por si e pelo seu desejo, é uma máscara ainda desafiadora para muitas delas. 
A repetição de queixas, ao contrário de um movimento esvaziado, pode surgir como uma forma de colocar limite à dominação masculina e o reestabelecimento de uma relação sem excessos e com equidade entre os gêneros (BRANDÃO, 2006). Visitar a delegacia e repetir as queixas, para muitas dessas mulheres, pode ser o indicativo de uma vontade de expressar sua liberdade, ainda que seja na mesma relação. Nesse sentido, concordamos com o trabalho em rede e a necessidade de um leque de políticas públicas como o próprio atendimento psicossocial ou outros fundamentais como os que promovem a autonomia financeira, mas, também, o investimento da polícia em construir formas de acolhimento que não seja a repetição de procedimentos que não respondem à complexidade desta violência, mas que componha junto com a rede de enfrentamento uma ação protetiva que promova, de fato, autonomia e capacidade de reconhecer e proteger-se de uma vida violenta.

Cabe à polícia, junto com as outras políticas públicas que compõem a rede de enfrentamento ressignificar, junto com a mulher, a vida, a liberdade e os seus direitos, nomeando para ela as máscaras de subalternidade e opressão, e permitindo que ventile no acolhimento de sua queixa a afirmação de sua dignidade, força e capacidade de escolha.

\section{CONSIDERAÇÕES FINAIS}

A pesquisa demonstrou que há uma regularidade nas categorias de compreensão utilizadas para a constituição dos atendimentos e dos saberes compartilhados pelo grupo de policiais pesquisados. Imersos em uma cultura institucional fortemente marcada pela homogeneização em contraposição à diversidade e a autonomia, repete-se procedimentos e formas de ser policial que não permitem desestabilizações diante dos embaraços causados pelos conflitos de gênero apresentados por mulheres em suas queixas de violência doméstica.

Enquanto eles esperam por uma ação institucional que os ensine como fazer, desconsideram a possibilidade de uma ação política advinda do próprio compromisso e do diálogo com os parceiros da rede de atendimento. Mais ainda: o impedimento do exercício de uma alteridade nos corredores da instituição policial constrói uma atuação que impede que os policiais possam confrontar o que é institucionalizado e, portanto, passível de crítica, com o investimento no pensamento, na interiorização e na reinvenção de si e do seu trabalho.

Ainda engessados na rigidez que marca a hierarquia institucional, a formação do policial e o seu trabalho cotidiano, eles pouco arriscam no sentido de construírem resistências subversivas que os coloquem em diferentes condições de reflexão para compreenderem as relações violentas entre homens e mulheres. A repetição dos padrões institucionais, nesse 
sentido, revela não só a ausência de uma necessária crise de compreensão diante desses casos em específico, como também a ausência de dispositivos que promovam a construção de saberes distintos para crimes e delitos diferenciados.

A criação de novos arranjos subjetivos que possam questionar as regulações institucionalizadas e as verdades que, a priori, definem o lugar da mulher e do saber policial no contexto da construção da queixa de violência doméstica, ainda é um desafio a ser alcançado. Quando foi possível ver estas novidades no campo de pesquisa foram processos, em sua maioria, fugazes, performatizados, sem que pudessem fazer parte da institucionalização do atendimento. No entanto, a existência de tais desestabilizações, ora assumidos, ora negligenciados, constituem um cotidiano de tensões e acordos que mesmo efêmeros, facilmente burlados e substituídos, podem ter a potência de produzir outras possibilidades de subjetivação.

Diante do receio de prejudicarem seus companheiros, as mulheres reiteradamente deslocam o fazer policial do lugar de coerção e resolutividade ao exigirem uma postura educativa para com seus agressores. Com vistas a manter suas histórias amorosas, a proteção dos filhos e o padrão de família sem a presença da violência, solicitam à polícia que reeduque seus homens, ensinando, através de uma atuação informal, uma linguagem relacional que não passe pela violência. $\mathrm{Na}$ dificuldade de se inventar outras linguagens que deem conta de acolher o então considerado ambíguo e confuso discurso das mulheres quando relatam a violência de gênero, a polícia constrói um lugar de culpabilização para a mulher, localizando nela a responsabilidade pela história de violência e se eximindo das mudanças nos padrões profissionais que cabe à polícia assumir.

Aos homens denunciados, por outro lado, fica reservado, apenas, o trânsito entre a delegacia e, nos casos mais graves, a cadeia. É a polícia que ocupa o lugar principal no tratamento dos agressores, em uma atuação na qual se impede que padrões violentos sejam problematizados através do diálogo. Prevista na Lei Maria da Penha, a atenção diferenciada ao agressor, tendo como cuidado a avaliação de cada caso, é negligenciada não só pela polícia, como também pela rede de atendimento da cidade. Tal condição impossibilita a inventividade de novas masculinidades e cristaliza ainda mais a padronização de respostas para casos e situações diferenciadas. 


\section{REFERÊNCIAS}

ABDALA, Claudia; SILVEIRA, Kátia; MINAYO, Maria Cecília de Souza. Aplicação da Lei Maria da Penha nas Delegacias de mulheres: o caso do Rio de Janeiro. Dilemas: Revista de Estudos de Conflito e Controle Social, Rio de Janeiro, v. 4, p.571-600, 2011. Out/nov/dez.

BRANDÃO, Elaine Reis. Violência Conjugal e o recurso feminino à policia. In: BRUSCHINI, Cristina; HOLANDA, Heloísa Buarque de. Horizontes Plurais: novos estudos de gênero no Brasil. São Paulo: Fundação Carlos Chagas, 1998. p. 51-84.

BRANDÃO, Elaine Reis. Renunciantes de Direitos? A problemática do enfrentamento público da violência contra a mulher: O caso da Delegacia da Mulher. Physis: Revista de Saúde Coletiva, Rio de Janeiro, v. 2, n. 16, p.207-231, 2006.

BRASIL. Presidência da República. Lei n.11.340, de 7 de agosto de 2006. Cria Mecanismos para coibir a violência doméstica e familiar contra a mulher, nos termos do $§ 8^{\circ}$ do art.226 da Constituição Federal, da Convenção sobre a Eliminação de Todas as Formas de Discriminação contra as mulheres e da Convenção Interamericana para Prevenir, Punir e Erradicar a Violência contra a Mulher; dispõe sobre a criação dos Juizados de Violência Doméstica e Familiar contra a Mulher; altera o Código de Processo Penal, o Código Penal e a Lei de execução Penal; e dá outras providências. [acesso em 2019 jul 12]. Disponível em: http://www.planalto.gov.br/ccivil_03/_Ato2004-2006/2006/Lei/L11340.htm. Acesso em: 15 ago.2019.

BRASIL. Presidência da República, Secretaria de Políticas para as Mulheres. Plano Nacional de Políticas para as Mulheres. Brasília, DF: Secretaria de Políticas para Mulheres; 2013.

BRASIL. Secretaria Nacional de Enfrentamento à Violência contra as Mulheres, Secretaria de Políticas para as Mulheres, Presidência da República. Política Nacional de enfrentamento da violência contra as mulheres. Brasília, DF: Secretaria Nacional de Enfrentamento à Violência contra as Mulheres. Brasília, DF: Secretaria de Políticas para Mulheres; 2011.

BUTLER, Judith. Problemas de Gênero: Feminismo e subversão da identidade. $2^{2} E d$. Rio de Janeiro: Civilização Brasileira, 2003.

CERTEAU, Michel de. A Invenção do Cotidiano I: a arte de fazer. Petrópolis: Editora Vozes, 1994.

DELEUZE, Gilles, GUATTARI, Félix. Mil Platôs: capitalismo e esquizofrenia. Rio de Janeiro: Ed. 34, 1995.

FOUCAULT, Michel. Microfísica do Poder. Rio de Janeiro: Graal, 2008.

FOUCAULT, Michel. Ditos e Escritos IV: Estratégia Poder-Saber. Rio de Janeiro: Forense Universitária, 2003.

FOUCAULT, Michel. Dits et Écrits IV. Paris: Gallimard, 1994.

FOUCAULT, Michel. A Verdade e as Formas Jurídicas. Rio de Janeiro: Nau Editora, 2002. 
GARCIA. Regina Leite. A difícil arte de pesquisar com o cotidiano. In: GARCIA, Regina Leite. (Org). Método Métodos Contramétodo. Rio de Janeiro: Cortez Editora, 2003.

PAIXÃO, Antônio Luiz. A Organização Policial numa área metropolitana. Revista Dados. Rio de Janeiro, v. 25, n. 1, p. 23-47. 1982

PONCIONI, Paula. O Modelo Policial Profissional e a Formação Profissional do Futuro Policial nas Academias de Polícia do Estado do Rio de Janeiro. Sociedade e Estado, Brasília, v. 3, n. 20, p.585-610, 2005. Set/dez.

ROLNIK, Suely. Cartografia Sentimental: transformações contemporâneas do Desejo. Porto Alegre: UFRGS Editora, 2011.

SANTOS, José Vicente Tavares dos. A arma e a flor: formação da organização policial, consenso e violência. Tempo Social: Revista de Sociologia da USP, São Paulo, v. 1, n. 9, p.155-168, maio 1997.

SCOTT, Joan. Gênero: uma categoria útil de análise histórica. Educação \& Realidade, Porto Alegre, v. 2, n. 20 , p. 71-100, jul./dez. 1995.

WEBER, Max. Economia e Sociedade. Brasília, DF: Editora Universidade de Brasília, 1999. 